\title{
Karaciğer Nakli Yapılmış Bir Hastada Açık Kalp Cerrahisi: Olgu Sunumu
}

\author{
Open Heart Surgery In A Patient With Liver Transplantation: A Case Report
}

\section{Melike Elif Teker, Önder Teskin}

Öz

Karaciğer nakli olan hasta sayısı arttıkça, geç dönemde gelişen kalp ve diğer sistem patolojileri nedeniyle cerrahi uygulamaları da sıklaşmıştır. Karaciğer nakli olan hastalarda koroner arter hastalığının görülme oranı artmaktadır. Karaciğer transplantı hastaları, asemptomatik olsa bile, koroner arter hastalığı için yüksek risk alt grubudur. Karaciğer transplantı gerçekleştirilen bir hastada koroner arter hastalığı gelişmesi, kötü bir prognostik faktördür; Bu nedenle, risk altındaki kişilerin belirlenmesi klinik önceliğe sahip olmalıdır. Bu çalışmamızda, on iki yıl önce karaciğer nakli uygulanan 68 yaşındaki bir erkek hastaya iskemik kalp hastalığı tanısı ile kardiopulmoner bypass uygulanmasının sunulması amaçlanmıştır. Hastaya sol internalmammarian arter ve otojenvengrefti kullanılarak üç damar için koroner arter bypass greft cerrahisi uygulandı. Preoperatif ve postoperatif herhangi bir komplikasyon gelişmedi. Daha önce karaciğer transplantasyonu yapılan hastalara, uygun merkezlerde koroner arter cerrahisi güvenli bir şekilde yap1labilir.

Anahtar Kelimeler: Karaciğer nakli, koroner bypass, koroner İskemi

\section{Abstract}

As the number of patients with liver transplantation increased, surgical applications were also frequent due to late-onset heart and other systemic pathologies. The incidence of coronary artery disease is increasing in patients with liver transplantation. Liver transplanted patients are a high risk subgroup for coronary artery disease, even if they are asymptomatic. Coronary artery disease is a predictor of poor outcomes in patients with liver transplantation; therefore, identification of those patients at risk for coronary artery disease should be a key clinical priority. In this study, it was aimed to present coronary artery bypass grafting surgery in a 68 -year-old male patient with previous liver transplantation 12 years ago. Coronary artery bypass grafting operation was performed using left internal mammarian artery and autogenous vein graft for three vessels. There was no complication in the pre- and post-operative periods. Coronary artery bypass grafting operation can be performed safely for patients with previous liver transplantaion in experienced centers.

KeyWords: Liver transplantation, coronary bypass, coronary ischemia

\section{Giriş}

Karaciğer nakliyle birlikte karaciğer yetmezlikli hastaların sağ kalım oranları artış göstermiştir. Karaciğer nakli olan hasta sayısı arttıkça da geç dönemde gelişen kalp ve diğer sistem patolojileri nedeniyle cerrahi uygulamaları da sıklaşmıştır [1]. Kalp cerrahisinde artan cerrahi deneyim, geliştirilen cerrahi teknikler, kullanılan ilaçların etkinliği ve güvenilirliğinin artışına paralel olarak karaciğer nakilli hastalarda koroner arter hastalığı geliştiğinde cerrahi tedavi seçeneği ön plana çıkmıştır [2]. Bu çalışmamızda 12 yıl önce karaciğer nakli yapılan ve koroner lezyonu nedeniyle cerrahi tedavi planlanan hastayı sunmayı amaçladık.

\section{Olgu sunumu}

Olgu sunumu hazırlanması öncesinde hastadan yazılı onam alındı.

12 yıl önce karaciğer nakli uygulanan, ikili immünsüpresif ajan (Tacrolimus ve mikofenilmofetil) tedavisi alan ve 1 yıl önce ani başlayan göğüs ağrısı nedeniyle sirkumfleks (CX) arter ve sol ön inen artere (LAD) stent takılan hastanın son 1 aydır özellikle eforile artan göğüs ağrısı ve nefes darlığı şikayetleri olması üzerine hastanemize başvurdu. Yapılan koroner anjiyografide CX ve LAD arterlere konulan stentin tıkandığ ve sağ koroner arter'de (RCA) de ciddi lezyonun olduğu saptanması üzerine açık kalp ameliyatı uygulamak için kliniğimize yatırıldı.
Biruni Üniversitesi Tıp Fakültesi, Kalp ve Damar Cerrahisi Kliniği, Florya, İstanbul, Türkiye.

Biruni University Faculty of Medicine, Cardiovascular Surgery Clinic, Florya, Istanbul, Turkey.

Çıkar Çatışması: Yazarlar çıkar çatışması bildirmemișlerdir.

Conflict of Interest: No conflict of interest was declared by the authors.

Finansal Destek: Yazarlar bu olgu için finansal destek almadıklarını beyan etmișlerdir.

Financial Disclosure: The authors declared that this case has received no financial support.

Geliș Tarihi / Received 12.07.2017

Kabul Tarihi / Accepted 27.07.2017

Yayın Tarihi / Published 01.12.2017

Sorumlu yazar / Corresponding author Melike Elif Teker

Adres/Address: Biruni Üniversitesi Hastanesi, Kalp ve Damar Cerrahisi Hastanesi, Eski Londra Asfaltı No:10 34070 Florya, İstanbul.

Telefon : +90 5062649670

E-posta: melikelif_teker@hotmail.com

Copyright 2017 ACEM 
Hastanın yapılan fizik muayenesinde patoloji saptanmadı. Kanama zamanı, pıhtılaşma zamanı, aspartat aminotransferaz ve alanin aminotransferaz değerleri ile bilirubin seviyeleri normal sınırlarda idi. Hasta gastroenteroloji bölümüne danışıldı. Kullandığı immünsüpresiflere devam edilmesi ve ek tedavi önermemesi üzerine aldığı medikal tedavi aynen devam ettirildi. Genel anestezi altında midsternalinsizyon ile mediastene girildi. Sol internal mamaryan arter (LiMA) ile sağ bacaktan safenvengreft hazırlandi. Heparinizasyonu takiben aortayaarteriyalkanül, sağ atriumatwostagevenözkanül yerleştirildi. 32 dereceye soğutulan hastada kardiopulmoner bypass (CPB) başlandı. Aortaya kros klemp altında aortik kök kanül ile antegrad kan kardiyoplejisi ile kardiyak arrest sağlandı. Sirasıly CX-safen ven, RCA-safenvendistalanastomozları 7/0 propilensütür ile yapıldı, daha sonra LAD-LIMA anastomozu yapılarak aortik kros klemp alındı ve kalp spontan çalıştı. Aortaya yan klemp konulduktan sonra CX ve RCA safenvenproksimal anastomozları yapıldı. Isı ve basınçlar uygun hale geldikten sonra CPB sonlandırılarak kanüller alındı. Kanama kontrolünü takiben sol toraks ve mediastene 2 adet toraks dreni konuldu. Kardiopulmoner bypass sırasında kalp boş olarak çalışıldı, venöz drenajı sağlamak için kanülün en geniş olanı seçildi ve venözkanül çok ilerletilmeden yerleştirilerek karaciğerde oluşabilecek venözdistansiyon engellendi.

Çapraz klemp zamanı 28 dakika, total bypass zamanı 42 dakika idi. Hasta 18 saat kalp ve damar cerrahisi yoğun bakımında takip edildikten sonra servise alınd. Postoperatif birinci günden itibaren immünsüpresif tedavisi tekrar başland. Herhangi bir komplikasyongelişmeyen hasta postoperatif 7 . günde taburcu edildi.

\section{Tartışma}

1990 yıllarında kalp cerrahisinde gelişmeler olmasına rağmen karaciğer nakli sonrasında sağ kalım oranının az olması, ameliyatın riskinin fazla olması, donör organ sayısının az olması nedeniyle koroner cerrahi girişim kontrendike olarak görülmekteydi. Zamanla karaciğer nakli sonrası sağ kalım oranının artması ve kalp cerrahisinde artan cerrahi deneyim, geliştirilen cerrahi teknikler, kullanılan ilaçların etkinliği ve güvenilirliğinin artışa paralel olarak cerrahi tedavi seçeneği ön plana çıkmıştır [2].

Karaciğer nakli sonrası 1 yılı aşkın bir sürre hayatta kalan hastalarda ölümcül olmayan nedenlere bağlı ölüm oranı $\% 49$,ve kardiovasküler hastalıklara bağlı ölüm oranı \%21 ve 3 yıl ve daha fazla yaşayan hastalarda ise non-hepatif ve nakilden bağımsız ölüm oranı \%12 iken, kardiovasküler nedenlere bağlı oran ise \%24'dür[3, 4].

Günümüzde karaciğer nakli sonrası kalp cerrahisi uygulanan hastalarda en önemli problem karaciğer disfonksiyonudur. Deb ve ark. [2], 13 karaciğer nakilli hastada açık kalp cerrahisi yapıldığını, bunların 6'sında (\%46) postoperatif erken dönemde geçici greftoklüzyonuna bağlı karaciğer enzimlerinde yükselme olduğunu ve taburculuk öncesinde hepsinin normale döndüğünü bildirmişlerdir[2]. Bizim olgumuzdaekstrakorporeal dolaşımla sırasında kalp boş olarak çalışıldı, venöz drenajı sağlamak için kanülün en geniş olanı seçildi ve venözkanul çok ilerletilmeden yerleştirilerek karaciğerde oluşabilecek venözdistansiyon engellendi. Böylelikle postoperatif dönemde karaciğer enzimlerinin normal sınırda kalması sağlandı.

Postoperatif dönemde yakın ve yoğun tıbbi takip gerektiren karaciğer nakilli hastalarda, normal kalp cerrahisi sonrası görülen atriyalfibrilasyon, akciğer ödemi, plevralefüzyon gibi komplikasyonların yaşandığı bildirilmektedir [5]. Bizim olgumuzda hiçbir komplikasyon görülmedi.
Kalp cerrahisi uygulanacak karaciğer nakilli hastalarda hala tartışmalı bir konu da steroid tedavisi alan ve kalp cerrahisi planlananlarda operasyon öncesi steroid dozunun uygulanıp uygulanmamasıdır. Ono ve ark. [5] karaciğer nakli yapılmış olan 15 hastaya stres dozunda steroid uygulaması yapmamışlardır ve bu hastalarda erken ölüm, allogreftrejeksiyon atağ 1 görülmemiştir ve 1999 yılından itibaren stres dozunda steroiduygulamasını terk etmişlerdir. Şu anda mevcut olan kısıtlı bilgilere dayanarak stres dozu steroid uygulaması, uzun süreli steroid tedavisi alan veya yüksek doz steroid uygulaması yapılan hastalar dişında önerilmemektedir. Bizim olgumuzda uzun yıllardır sterod kullanmasından dolayı operasyon öncesi kullandığı miktarda uyguladık.

Clarke ve ark. [6] yaptığı bir çalışmada kalp cerrahisi sonrası koruyucu amaçlı kullanılan aspirinin karaciğer nakilli hastada trombositemiye bağlı kanama riskini arttırabileceğini, ayrıca anjiotensin dönüştürücü enzim inhibitörlerinin renaldisfonsiyonun bozulmasına katkıda bulunabileceğini göstermişlerdir. Fakat günümüzde bulunan yeni veriler ise yakın izlemle güvenlik ve tolerabilitelerini desteklemektedir[7]. Dahası, kardiyovasküler etkilerin yanı sıra hepatositlere karşı doğrudan eylemleri nedeniyle statinlerinkaraciğer hastalığında yararlı olabileceğine dair kanıtlar da bulunmaktadır[8]. Dolayısıyla, olgu yakın kontrol altında olmak kaydı ile aspirin ve statin tedavisi ile taburcu edildi.

Sonuç olarak, yeterli vaka serisi olmamasına rağmen kalp cerrahisi karaciğer nakli yapılmış olgularda güvenli bir şekilde uygulanabilir. Bu hastalarda karaciğer fonksiyonlarının postoperatif erken dönemde yakın takip edilmesi ve greft disfonksiyonunu önlemek amaciyla immünsüpresif tedavinin düzenli bir şekilde uygulanması gerekmektedir.

\section{Kaynakça}

1. Faruk C, İsmail H Ö, Mehmet A.Ş, et al. Karaciğer nakli yapılmış hastada açık kalp cerrahisi. Gülhane Tıp Dergisi 2012; 54: 165-7.

2. Harrington PB, McAlexander WW, Bryant AS, et al. Outcomes of Patients Who Undergo Cardiac Surgical Procedures After Liver Transplantation. Ann Thorac Surg. 2017; 103:541-5.

3. Vogt DP, Henderson JM, Carey WD, Barnes D. The long term survival and causes of death in patients who survive at least 1 year after liver transplantation. Surgery 2002;132:775-80.

4. Canzanello VJ, Schwartz L, Taler SJ. et al. Evolution of cardiovascular risk after liver transplantation: a comparison of cyclosporine A and tacrolimus (FK506). Liver Transpl Surg 1997; 3: $1-9$.

5. Ota T, Rocha R, Wei LM, Toyoda Y, Gleason TG, Bermudez C. Surgical outcomes after cardiac surgery in liver transplant recipients. Thorac Cardiovasc Surg. 2013; 145:1072-6.

6. Clarke AT, Mills PR. Atorvastatin associated liver disease. Dig Liver Dis 2006; 38:772-7.

7. Law M, Rudnicka AR. Statin safety: a systematic review. Am J Cardiol 2006;97:52-60.

8. Onofrei MD, Butler KL, Fuke DC, Miller HB. Safety of statin therapy in patients with preexisting liver disease. Pharmacotherapy 2008;28:522-9. 